\title{
Early extinction after fear conditioning yields a context-independent and short-term suppression of conditional freezing in rats
}

\author{
Chun-hui Chang ${ }^{1}$ and Stephen Maren ${ }^{1-3}$ \\ ${ }^{1}$ Department of Psychology, University of Michigan, Ann Arbor, Michigan 48109-1043, USA; ${ }^{2}$ Neuroscience Program, University of \\ Michigan, Ann Arbor, Michigan 48109-1043, USA
}

\begin{abstract}
Extinction of Pavlovian fear conditioning in rats is a useful model for therapeutic interventions in humans with anxiety disorders. Recently, we found that delivering extinction trials soon (15 $\mathrm{min}$ ) after fear conditioning yields a short-term suppression of fear, but little long-term extinction. Here, we explored the possible mechanisms underlying this deficit by assessing the suppression of fear to a CS immediately after extinction training (Experiment 1 ) and the context specificity of fear after both immediate and delayed extinction training (Experiment 2). We also examined the time course of the immediate extinction deficit (Experiment 3). Our results indicate that immediate extinction produces a short-lived and context-independent suppression of conditional freezing. Deficits in long-term extinction were apparent even when the extinction trials were given up to $6 \mathrm{~h}$ after conditioning. Moreover, this deficit was not due to different retention intervals that might have influenced the degree of spontaneous recovery after immediate and delayed extinction (Experiment 4). These results suggest that fear suppression under immediate extinction may be due to a short-term, context-independent habituation process, rather than extinction per se. Long-term extinction memory only develops when extinction training occurs at least six hours after conditioning.
\end{abstract}

Pavlovian fear conditioning and extinction are important behavioral models for studying the brain mechanisms underlying the acquisition, storage, retrieval, and suppression of traumatic fear (LeDoux 2000; Maren 2001, 2005; Kim and Jung 2005). In this procedure, an emotionally neutral stimulus, such as a tone, is paired with an aversive stimulus (US), such as an electric foot shock. After a few tone-foot shock pairings, the previous neutral tone becomes a potent conditioned stimulus (CS) and acquires the ability to elicit fear responses, such as freezing (CR). However, with repeated presentations of the CS-alone, the previously acquired CR gradually subsides, a process called extinction (Davis et al. 2003; Maren and Quirk 2004; Kim and Jung 2005; Myers and Davis 2007). The behavioral processes and the underlying neural mechanisms of extinction have attracted extensive attention in contemporary research of learning and memory (Bouton et al. 2006). Indeed, it has been suggested that failure to extinguish fear may contribute to post-traumatic stress disorder (PTSD) (Bouton et al. 2001; Rothbaum and Davis 2003). To avoid the possible long-term consequences and costs of PTSD or other anxiety disorders, clinical interventions are essential. While early interventions may manage the stress response to trauma, their efficacy has been challenged, because the acute intense stress of the traumatic experience might actually exacerbate relapse of fear (McNally 2003; Rothbaum and Davis 2003; Gray and Litz 2005). Thus, it is essential to learn when these interventions generate the best long-term extinction of fear responses.

In a recent study, we demonstrated that delivering extinction trials shortly after fear conditioning yields poor long-term fear reduction (Maren and Chang 2006; but, see Myers et al. 2006). We observed that conditional freezing decreased during extinction training, but recovered completely $24 \mathrm{~h}$ later. This was true even when we gave 225 massed extinction trials $15 \mathrm{~min}$ after fear conditioning. However, in these experiments the within-session decrease in fear in rats that underwent extinction was similar to that

${ }^{3}$ Corresponding author.

E-mail maren@umich.edu; fax (734) 763-7480.

Article is online at http://www.learnmem.org/cgi/doi/10.1101/lm.1085009. in rats that were not exposed to extinction trials. Thus, it is unclear to what extent the short-term fear suppression we observed was due to a loss of fear to the context, the auditory CS, or both. It is also not clear whether fear suppression was due to extinction or, alternatively, another learning process such as habituation.

To examine these issues further, in the present study we first assessed fear suppression to the auditory CS after immediate extinction by probing CS fear 15 min after extinction training. In a second experiment, we examined whether short-term fear suppression to the CS is renewed outside of the extinction context, as context specificity is one of the hallmarks of extinction (Bouton 2002; Ji and Maren 2007). In the third and fourth experiments, we examined the temporal delay necessary between conditioning and extinction to yield long-term suppression of fear. In our previous work (Maren and Chang 2006), all phases of training were conducted in the same context. Therefore, fear to the context decreased conditional freezing to the tone, particularly when extinction occurred shortly after conditioning, a time at which sensitized context fear was high. In an effort to isolate fear to the tone CS during extinction, we conducted extinction and test sessions in a context that was different from the conditioning context (i.e., an $\mathrm{ABB}$ procedure, where each letter denotes the context used for conditioning, extinction, and test, respectively). Our results reveal that delivering CS-alone trials shortly after fear conditioning produces a short-lived and context-independent suppression of freezing. This fear suppression may be due to a short-term, contextindependent habituation process, rather than extinction. Furthermore, poor long-term extinction occurs even when the extinction trials were administered up to $6 \mathrm{~h}$ after conditioning.

\section{Results}

Experiment 1: Does immediate extinction training produce short-term decrements in fear to an auditory CS?

Previous work from our laboratory has revealed similar decrements in freezing during extinction training in animals exposed to either 
the CS or the context alone (Maren and Chang 2006). The present experiment aimed to assess whether decrements in fear in rats receiving CS extinction trials involved a loss of fear to the CS itself, as opposed to a loss of context fear.

Rats were submitted to a standard fear-conditioning procedure in which an auditory CS was paired with a noxious foot shock US in a novel chamber. After a 15-min delay, rats were placed in another novel context, where half of the animals received 45 extinction trials in which the CS was presented alone (EXT), while the other half of the animals remained in the chambers without the presentation of either the CS or US (NOEXT); these rats served as the nonextinguished control group. Fifteen minutes after extinction, both groups were returned to the extinction context and a single CS was presented to assess freezing to the CS shortly after immediate extinction and to avoid possible extinction in the EXT group due to CS presentations. Forty-eight hours after extinction, rats were tested for their fear to the CS again by returning them to the extinction context and presenting five auditory CSs.

Freezing behavior during the conditioning session is shown in Figure 1A. Freezing levels were very low before the first conditioning trial, and then increased in frequency thereafter. There was an equivalent increase in freezing across trials in both groups (extinction $\times$ trials, $F_{(6,84)}<1$ ). Freezing behavior during the extinction session is shown in Figure 1B. As reported in our previous study (Maren and Chang 2006), recently conditioned rats exhibited high levels of freezing before the first extinction trial $\left(\mathrm{EXT}=64.4 \pm 11.1\right.$, NO-EXT $\left.=73.3 \pm 8.9 ; F_{(1,14)}<1\right)$, probably due to shock-induced sensitization of fear. This was evident even though rats experienced a context shift in between conditioning and extinction. Freezing behavior in both groups showed an equivalent decline in freezing across the sessions (extinction $\times$ block, $\left.F_{(9,126)}=1.05\right)$.

Despite the similar reduction in freezing in the EXT and NOEXT groups, rats that had received CS-alone extinction trials showed significantly greater short-term suppression of fear to the CS in the probe trial (Fig. 1C). Before the CS onset, EXT and NO-EXT groups showed equivalent and low freezing levels (EXT $=$ $19.1 \pm 9.8$, NO-EXT $\left.=8.5 \pm 3.4 ; F_{(1,14)}=1.005, P=0.33\right)$. Relative to NO-EXT rats, freezing levels were significantly lower in the EXT group compared with nonextinguished controls when presented with a single CS $15 \mathrm{~min}$ after extinction. $\left(F_{(1,14)}=7.81, P<0.02\right)$. However, fear in the EXT animals exhibited substantial spontaneous recovery when tested $24 \mathrm{~h}$ after extinction; there was no significant difference between the baseline freezing before tone onset $\left(\mathrm{EXT}=15.5 \pm 8.2\right.$, NO-EXT $\left.=13.9 \pm 8.0 ; F_{(1,14)}<1\right)$, or between the groups in the long-term retention test $\left(F_{(1,14)}=3.17, P\right.$ $=0.09$ ) (Fig 1D). Thus, immediate extinction generated a significant, but short-lived suppression of conditional fear.

\section{Experiment 2: Does immediate extinction training produce a context-specific suppression \\ of conditional fear?}

A hallmark of extinction is its context specificity: Extinguished fear returns or "renews" when the CS is presented outside of the extinction context (Bouton 2002; Ji and Maren 2007). In the previous experiment, we examined the efficacy of short-term extinction by giving a probe right after immediate extinction trials. Our results showed that there was a short-lived suppression of freezing to the CS shortly after extinction. In the present experiment, we further examine whether this short-lived suppression in freezing exhibits context specificity. Rats were conditioned to five tone-shock trials in a novel context. Fifteen minutes (IMMED) or $24 \mathrm{~h}$ (DELAY) after conditioning, they received 45 extinction trials in another context. To access the context dependence of the short-term fear suppression, five tones were presented either inside (SAME) or outside (DIFF) the extinction context $15 \mathrm{~min}$ after extinction training.

Behavior during the conditioning session was similar to that reported in Experiment 1 (data not shown). Freezing behavior in the IMMED and DELAY groups during early extinction, late extinction, and retrieval testing is shown in Figure 2. Freezing levels were high at the beginning of extinction (Early Ext) and decreased significantly at later trials (Late Ext) in both groups. However, when tested $15 \mathrm{~min}$ after extinction, freezing levels in the IMMED group remained low regardless of test context (Fig. 2A, Test), while freezing in the DELAY group was significantly higher outside than inside the extinction context (Fig. 2B, Test). There was no significant interaction between test period and renewal context in the IMMED group $\left(F_{(2,44)}<1\right)$, while the interaction reached significance in the DELAY group $\left(F_{(2,44)}=4.01, P<0.03\right)$. Thus, early extinction yields a context-independent suppression of freezing when tested shortly after extinction.

\section{Experiment 3: How much time must elapse after conditioning for extinction training to yield long-term fear suppression?}

In the previous two experiments, we demonstrated that immediate extinction soon after conditioning generates a short-lived and
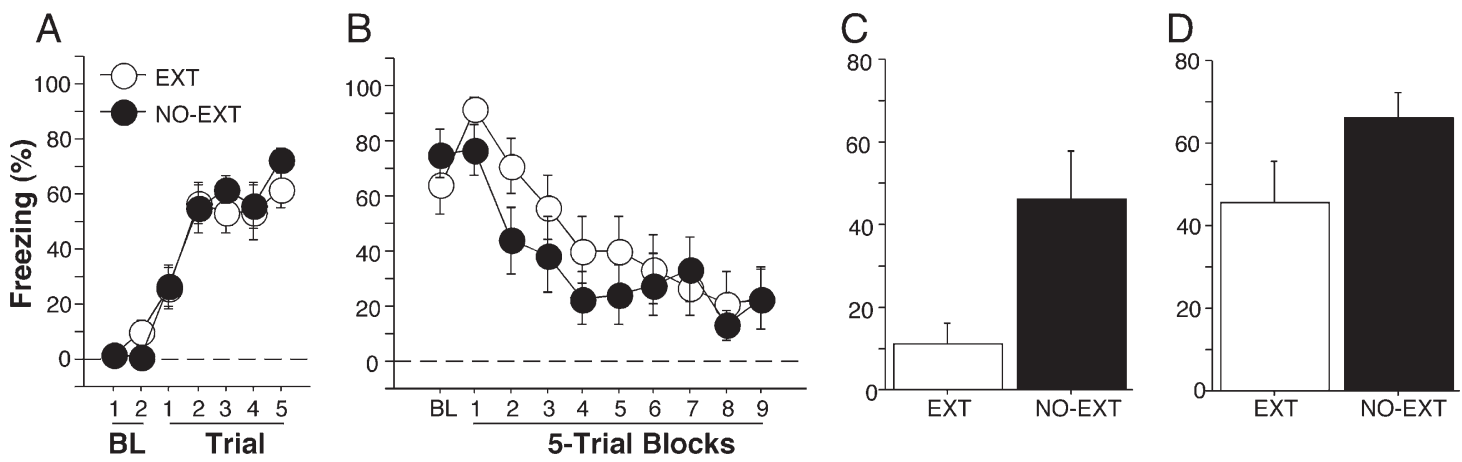

Figure 1. Probe CS after immediate extinction. (A) Percentage of freezing behavior during conditioning. Data are 1-min averages for the periods before (baseline, $\mathrm{BL}$ ) and after each of five tone-shock conditioning trials. (B) Percentage of freezing behavior during the extinction session, which occurred $15 \mathrm{~min}$ after conditioning. Control rats did not receive CS presentations during extinction (NO-EXT). (C) Percentage of freezing behavior during the probe CS $15 \mathrm{~min}$ after extinction. Baseline freezing data were averaged and subtracted from the freezing level during probe CS to yield normalized freezing. $(D)$ Normalized average percentage of freezing across test trials during retention test $48 \mathrm{~h}$ after conditioning. All data are means \pm SEM. 

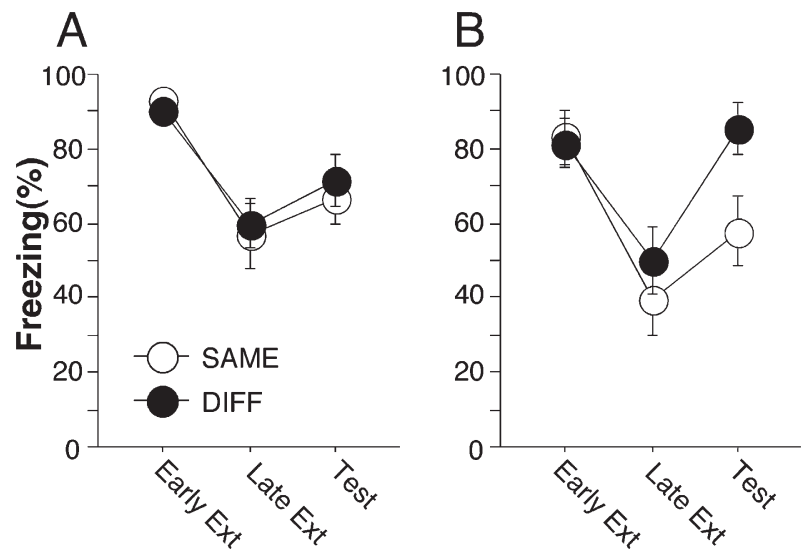

Figure 2. Renewal of fear response immediately after immediate or delayed extinction. Shown are averaged two-trial block percentages of freezing levels during early extinction, late extinction, and early renewal in immediate $(A)$ and delayed $(B)$ extinction conditions. All data are means \pm SEM.

context-independent suppression of fear. In the present experiment, we further examined the relationship of the timing of extinction relative to conditioning by giving extinction trials at different delays after conditioning. Rats were trained with five tone-foot shock pairings in one context. They next received 45 extinction trials $15 \mathrm{~min}, 1 \mathrm{~h}, 6 \mathrm{~h}$, or $24 \mathrm{~h}$ later in a different context, and control groups at each time point received no extinction training. All rats were tested to 45 tone-alone presentations $48 \mathrm{~h}$ after conditioning.

Behavior during the conditioning and extinction sessions was similar to that reported in Experiments 1 and 2 (data not shown). Freezing behavior during the entire retention session is shown in Figure 3. There was no significant difference in freezing levels for nonextinguished controls at different delays $(P=0.06)$, so they were collapsed into a single NO-EXT group $(n=32)$. During baseline, there was no significant difference in freezing for $15 \mathrm{~min}$, $1 \mathrm{~h}, 6 \mathrm{~h}$, and $24 \mathrm{~h}(P>0.05)$, while NO-EXT was significantly lower than 15 -min and 1 -h groups $(P \mathrm{~s}<0.05)$. During the first five tones, only animals receiving extinction trials $24 \mathrm{~h}$ after conditioning demonstrated significant long-term extinction of fear memory: There was no difference in freezing levels of NO-EXT, 15-min, 1-h, and 6-h groups, and the freezing level of the 24-h group was significantly lower than any of the other groups (Ps $<0.04)$. Interestingly, animals in the 15-min, 1-h, and 6-h groups demonstrated savings of extinction training, that is, their freezing levels in these groups declined faster compared with the NO-EXT controls, while the 24 -h group remained low across the whole session. There was a significant main effect of delay $\left(F_{(4,59)}=5.77, P\right.$ $=0.0005)$ and a significant interaction in delay and block $\left(F_{(36,531)}\right.$ $=4.57, P<0.0001)$. Thus, administering an extinction trial up to 6 $\mathrm{h}$ after conditioning failed to extinguish long-term fear response, but all groups exhibited savings during subsequent extinction.

\section{Experiment 4: Is the immediate extinction deficit due to} a longer extinction-retention test interval?

In the previous experiment, we demonstrated that giving extinction trials up to $6 \mathrm{~h}$ after conditioning failed to extinguish longterm fear response. However, animals receiving extinction trials up to $6 \mathrm{~h}$ after conditioning were tested $48 \mathrm{~h}$ after extinction, while animals in the 24 -h group were tested $24 \mathrm{~h}$ after extinction. It is possible that the 24-h group showed less freezing during the retention test because of the more limited opportunity for spontaneous recovery after extinction compared with the other groups. Thus, in this experiment, we equated the extinction-retention test interval for both immediate (15 $\mathrm{min})$ and delayed ( $24 \mathrm{~h}$ ) groups: All animals were tested $48 \mathrm{~h}$ after extinction training.

Behavior during the conditioning and extinction sessions was similar to that reported in Experiments 1, 2, and 3 (data not shown). Figure 4 shows the average freezing during the first five trials of the retention test. There was a significant interaction between delay and extinction $\left(F_{(1,24)}=4.34, P<0.05\right)$. Planned comparisons indicated that only rats in the delayed extinction condition exhibited significant extinction relative to their noextinction controls $(P<0.05)$. Thus, the greater recovery of fear after an immediate extinction procedure in Experiment 3 was not due to the longer extinction-test interval used in that experiment. This confirms our previous report that immediate extinction produces only a short-term fear suppression that rapidly recovers within $24 \mathrm{~h}$ after extinction (Maren and Chang 2006).

\section{Discussion}

In the present study, we examined the properties of short-term fear suppression after immediate extinction and the time course between conditioning and the delivery of CS-alone trials required for long-term fear suppression. Our major finding is that delivering CS-alone trials soon after fear conditioning generates a short-lived and context-independent suppression of fear. Longterm extinction was minimal when CS-alone trials were administered shortly after conditioning (15 min), and this effect persisted up to $6 \mathrm{~h}$ after fear conditioning. These results further support the view that early intervention shortly after a traumatic experience may not be effective in producing long-term fear suppression.

A critical question that emerges from these experiments is what psychological process underlies the temporary and contextindependent suppression of conditional freezing to an auditory CS when extinction trials are administered soon after conditioning. One possibility is that short-term habituation, rather than extinction, accounts for the response loss we have observed during the presentation of CS-alone trials shortly after fear conditioning. Consistent with this possibility, short-term habituation often exhibits spontaneous recovery over 24-h retention intervals (Thompson and Spencer 1966; McSweeney and Swindell 2002). And, unlike long-term extinction, short-term habituation is typically not context dependent (Bouton 2004). That is, extinction is associated with a loss of responding that is specific to the extinction context, while habituation is associated with a loss of responding in any test context. In the present experiments, we observed that exposure to CS-alone trials shortly after fear conditioning resulted in a context-independent loss of fear, while

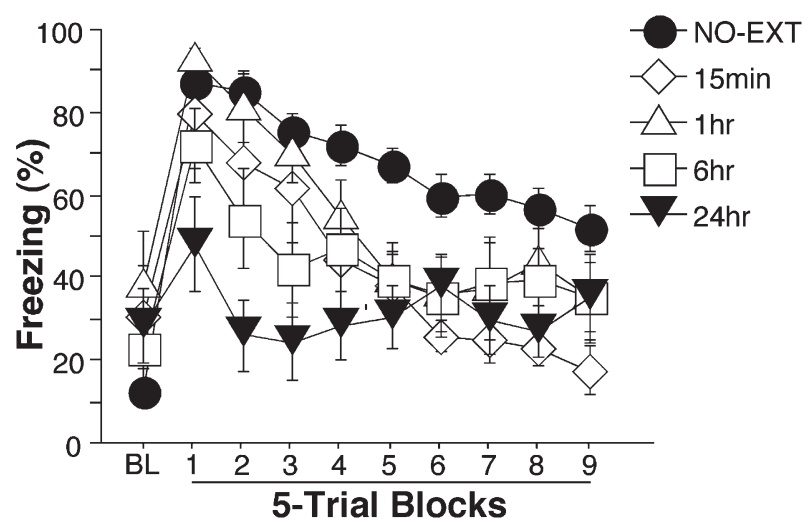

Figure 3. Percentage of freezing levels during retention test after different delays between conditioning and extinction sessions. All data are means \pm SEM. 


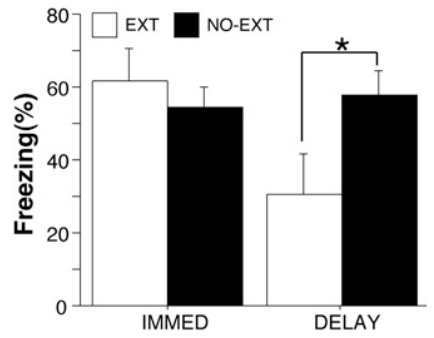

Figure 4. Percentage of freezing levels during retention test with equated extinction-retention test intervals. All data are mean \pm SEM. ${ }^{*} P<0.05$.

delayed extinction induced a long-lived and context-dependent suppression in fear response. This suggests that different processes mediate fear under these conditions: The former mediated by habituation and the latter by extinction.

According to this view, extinction learning itself may have been impaired when extinction training was conducted soon after conditioning. According to Wagner's SOP model (Wagner 1982), for example, a CS presented during extinction training will excite conditional responding when it activates a representation of the US in the A2 state. Subsequent presentations of the CS will promote inhibitory (extinction) learning when CS activity in A1 coincides with US activity in A2. As we have seen, however, conditional fear in the IMMED condition is substantial prior to the delivery of the first CS-alone extinction trial. Hence, it is possible that elements of both the CS and US are primed in A2 (perhaps by contextual stimuli common to the conditioning context or the recent delivery of CSs and USs during conditioning). This arrangement would retard inhibitory (or excitatory) learning between the CS and US. Short-term reductions in conditional responding as the CS might then result from additional self-generated priming of the CS to the A2 state. After a delay, we would posit that fewer CS and US elements are represented in the A2 state, and conditions therefore favor coincident activation of the CS to A1 and US to A2 that promotes extinction.

Interestingly, we found that the fear suppression generated by delayed CS-alone trials was context specific within 15 min of the end of the extinction session. To our knowledge, this is the first report of fear renewal within minutes of the end of extinction training. Indeed, most experiments have examined renewal effects at least $24 \mathrm{~h}$ after the end of extinction (Bouton et al. 2006). Insofar as time (both intertrial interval effects and the passage of time between extinction and retention) has been posited to regulate memory retrieval after extinction (Morris et al. 2005; Bouton and Garcia-Gutierrez 2006), these results indicate that a shift in environmental context that occurs within the temporal context of an extinction session is sufficient to yield a robust renewal of fear. Indeed, both short- and long-term extinction memories exhibit context dependence as long as extinction commences at least $24 \mathrm{~h}$ after conditioning.

The neurobiological basis for the long-term extinction of fear has received considerable attention in recent years (Bouton et al. 2006; Quirk et al. 2006; Ji and Maren 2007; Quirk and Mueller 2008). Interactions among the hippocampus, the medial prefrontal cortex (mPFC), and the amygdala are thought to play a role in limiting the expression of fear responses. For example, there is growing evidence that the mPFC is positioned to reduce amygdala output by exciting inhibitory interneurons in the intercalated nuclei (Quirk et al. 2000; Milad and Quirk 2002; Pare et al. 2004; Santini et al. 2004). Moreover, the hippocampus may modulate this circuitry to gate when and where extinction is expressed (Thierry et al. 2000; Hobin et al. 2003; Sotres-Bayon et al. 2004), a feature that is critical for the contextual regulation of fear (Hobin et al. 2003; Maren 2005). With regard to the present experiments, it is not clear whether this circuit is also engaged by the delivery of CS-alone trials shortly after fear conditioning. One possibility is that neuronal activity in the amygdala is suppressed during the extinction session without actually engaging the inhibitory circuits stated above. Indeed, amygdala activity in response to novel stimuli, including acoustic tones, is known to rapidly habituate (LaBar et al. 1998; Herry et al. 2007), and this habituated neuronal response might reduce the behavioral expression of fear under some conditions (Kamprath and Wotjak 2004). Interestingly, the cellular mechanisms within the amygdala for early and late extinction may be different (Herry et al. 2006).

Another issue we explored in the present experiments is the amount of time that must elapse between conditioning and the delivery of CS-alone trials to promote long-term extinction. Our results revealed that even up to $6 \mathrm{~h}$ after conditioning, the delivery of extinction trials produced a minimal long-term suppression of conditional freezing the following day. Although we were not able to obtain reliable extinction when CS-alone trials were delivered within $6 \mathrm{~h}$ of conditioning, it should be noted that in both rats (Quirk et al. 2000; Milad and Quirk 2002; Myers et al. 2006) and humans (Phelps et al. 2004; Kalisch et al. 2006; Milad et al. 2007) long-term extinction has been reported within an hour of fear conditioning. However, in these studies, relatively weak unconditioned stimuli were used, and the level of fear aroused during conditioning may be critical in determining the sensitivity of the fear memory to early extinction. Indeed, we found that reducing the number of conditioning trials enabled extinction shortly after conditioning (Maren and Chang 2006).

Despite showing deficits in long-term extinction, all of the groups that underwent extinction in the third experiment exhibited faster response loss upon subsequent extinction training relative to rats extinguished for the first time. This indicates that there were savings for the original extinction training, even though it was not evident in the degree of fear suppression at the outset of the retention test. This pattern of savings is also observed during the expression of long-term habituation, which is typically manifest as a more rapid rate of habituation relative to naïve controls (Carew et al. 1972). Hence, more rapid fear loss during the second exposure to CS-alone trials is consistent with the possibility that a habituation, rather than an extinction process mediates response loss after early extinction (Thompson and Spencer 1966). An alternative explanation of the savings we observed is that the extinction learning under immediate extinction was impaired but not totally abolished, which led to a faster fear loss during the retention test.

In our previous work, we argued that arousal as a result of returning to the context of recent trauma (shock in this case) or associative fear of the context may have led to the failure of longterm fear suppression in the immediate extinction rats (Maren and Chang 2006). In these experiments, all of the behavioral sessions were conducted in the same context (i.e., AAA, where each letter denotes conditioning, extinction, and retention test, respectively), and contextual fear may have contributed to the failure to extinguish recent fear. However, in the present experiments, we extinguished the animals outside of the conditioning context (ABB design) in an attempt to minimize the influence of context fear on extinction. Even under these conditions, recent shock sensitized fear in the novel context, resulting in high baseline freezing levels before the onset of the extinction trials. Although we cannot entirely rule our the contribution of context fear to early extinction impairments, it seems more likely that they are due to the recent sensitization of fear, rather than associative fear to the context per se. 
Early psychological interventions after a traumatic event are not always effective (Bisson et al. 1997; Rothbaum and Davis 2003; Gray and Litz 2005). The present work indicates that CS-alone exposure soon after conditioning yields a short-term habituation rather than a long-term extinction of the fear response. These results suggest that delayed interventions may be more effective in reducing pathological fear. Understanding the factors that contribute to the long-term suppression in fear memory is the next important step in developing optimal clinical interventions for psychological trauma in humans.

\section{Materials and Methods}

\section{Experiment 1: Does immediate extinction training produce short-term decrements in fear to an auditory CS?}

\section{Subjects and behavioral apparatus}

The subjects were 16 male Long-Evans rats (250-330 g; Blue Spruce) obtained from a commercial supplier (Harlan Sprague Dawley). They were housed in individual cages with 14-h light/ 10-h dark cycle (lights on at 7:00 am), and allowed food and water ad libitum. During the first 5 days, they were handled for $10 \mathrm{sec}$ to habituate them to the experimenter.

Eight identical observation chambers $(30 \times 24 \times 21 \mathrm{~cm}$; MED-Associates) were used in all experiments. The chambers were constructed of aluminum (side walls) and Plexiglas (rear wall, ceiling, and hinged front door) and were situated in soundattenuating cabinets located in a brightly lit and isolated room. The floor of each chamber consisted of 19 stainless steel rods ( $4 \mathrm{~mm}$ in diameter) spaced 1.5 -cm apart (center-to-center). Rods were wired to a shock source and solid-state grid scrambler (MEDAssociates) for the delivery of foot shock US ( $0.5 \mathrm{sec} ; 1 \mathrm{~mA})$. A speaker mounted outside a grating in one wall of the chamber was used for the delivery of acoustic CS ( $2 \mathrm{sec} ; 80 \mathrm{~dB} ; 2 \mathrm{kHz}$ ).

Each conditioning chamber rested on a load-cell platform that was used to record chamber displacement in response to each rat's motor activity and acquired online using Threshold-Activity software (MED-Associates). The output of each chamber's load cell was set to a gain that was optimized for detecting freezing behavior (somatomotor immobility, except that necessitated by breathing). Load-cell amplifier output $(-10$ to $+10 \mathrm{~V})$ from each chamber was digitized. Absolute values of the load-cell voltages were then computed and multiplied by 10 to yield a scale that ranged from 0 to 100 . For each chamber, load-cell voltages were digitized to $5 \mathrm{~Hz}$, yielding one observation every $200 \mathrm{msec}$. Freezing was quantified (Maren 1998) by computing the number of observations for each rat that had a value less than the freezing threshold (load-cell activity $=10$ ). We scored an observation as freezing if it fell within a continuous group of at least five observations that were all less than the freezing threshold. Thus, freezing was only scored if the rat was immobile for at least $1 \mathrm{sec}$. Freezing was determined during each 1-min intertrial interval after the CS offset during conditioning, extinction, probe, and the retention test, and during the minutes preceding the first CS presentation during extinction training.

Two distinct contexts were used in this experiment. For the first context (context A), a $15 \mathrm{~W}$ house light mounted opposite the speaker was turned on, and room lights remained on. The chambers were cleaned with a $1 \%$ acetic acid solution. To provide a distinct odor, stainless-steel pans containing a thin layer of this solution were placed underneath the grid floors before the rats were placed inside. Ventilation fans in each chest supplied background noise $(65 \mathrm{~dB})$. Rats were transported to this context in white plastic boxes. For the second context (context B), all room and chamber house lights were turned off. A pair of $40 \mathrm{~W}$ red lights provided illumination. Additionally, the doors on the soundattenuating cabinets were closed, the ventilation fans were turned off, and the chambers were cleaned with $1 \%$ ammonium hydroxide solution. Also, stainless-steel pans containing a thin layer of the same solution were placed underneath the grid floors before the rats were placed inside to provide a distinct odor. Rats were transported to this context in black plastic boxes.

\section{Procedure}

Rats were submitted to four phases of training: fear conditioning, extinction, probe, and extinction-retention test. For fear conditioning, rats received five tone-foot shock trials (60-sec intertrial interval) beginning $3 \mathrm{~min}$ after being placed in the chambers (context A). Fifteen minutes later, rats received 45 tone-alone presentations for fear extinction (EXT, $n=8$ ) in the other context (context B). For no-extinction controls (NO-EXT, $n=8$ ), rats were placed in the chamber for the same amount of time, but were not exposed to the tone CS. Another $15 \mathrm{~min}$ after immediate extinction, all animals were returned to extinction context and presented with one single probe CS. Two days following conditioning, all rats were returned to the extinction context again and exposed to five CS-alone presentations.

\section{Data analysis}

All behavioral data are expressed as means and standard error of the means (SEM) and analyzed by analysis of variance (ANOVA). Post-hoc comparisons in the form of Fisher's PLSD tests were performed after a significant $F$ ration.

\section{Experiment 2: Does immediate extinction training produce a context-specific suppression of conditional fear?}

\section{Subjects and behavior apparatus}

The subjects were 64 adult male Long-Evans rats (250-330 g) obtained and housed as described in Experiment 1. The conditioning chambers described in Experiment 1 comprised the behavior apparatus.

Three distinct contexts were used in this experiment. The first two were the same as described in Experiment 1. For the third context (Context C), the room lights were on and the house lights and fans were off. Rubber and black plastic sheets were placed above the rods. The chambers were cleaned with a 70\% ethanol solution. To provide a distinct odor, stainless-steel pans containing a thin layer of this solution were placed underneath the grid floors before the rats were placed inside. Rats were transported to this context in white plastic boxes with beddings on the floor.

\section{Procedure}

Rats were submitted to three phases of training: fear conditioning, extinction, and retrieval testing ( $\mathrm{ABC}$ renewal testing). For fear conditioning, rats received five tone-foot shock trials in context A. Fifteen minutes (IMMED) or $24 \mathrm{~h}$ (DELAY) after conditioning, rats were presented with 45 tones either in context $\mathrm{B}$ or context $\mathrm{C}$ for fear extinction. Another $15 \mathrm{~min}$ after extinction, all rats were presented with five tones in context B for renewal testing. The day before conditioning, the animals were exposed to the nonextinction context in order to familiarize them with each test context. The actual contexts for extinction and testing were counterbalanced across groups, yielding a total of four groups in a $2 \times 2$ (extinction time $\times$ test context) design. The four groups were IMMED/SAME, IMMED/DIFF, DELAY/SAME, and DELAY/DIFF, with 16 rats per group. The labels SAME and DIFF referred to whether the CS was tested in a same context as the extinction context (SAME) or in a different context from the extinction context (DIFF).

\section{Data analysis}

The average percentage of freezing during two trials during early extinction (first two trials), late extinction (last two trials), and early renewal (first two trials) were used for the data analyses, as described in Experiment 1. In order to test the renewal effect, rats failed to show extinction at late extinction trials, that is, the 
freezing level remained the same or even higher than early trials and were excluded from further analyses. It leads to the number of animals in each group as following: IMMED/SAME $=11$, IMMED/ DIFF $=13$, DELAY $/$ SAME $=12$, and DELAY $/$ DIFF $=12$.

\section{Experiment 3: How much time must elapse after conditioning for extinction training to yield long-term fear suppression?}

\section{Subjects and behavior apparatus}

The subjects were 64 adult male Long-Evans rats (250-330 g) obtained and housed as described in Experiment 1. The conditioning chambers described in Experiment 1 comprised the behavior apparatus.

\section{Procedure}

Rats were submitted to three phases of training: fear conditioning, extinction, and extinction retention test. For fear conditioning, rats received five tone-foot shock trials in context A. Fifteen minutes, $1 \mathrm{~h}, 6 \mathrm{~h}$, or $24 \mathrm{~h}$ later, rats received 45 tone-alone presentations for fear extinction (EXT, $n=8$ per condition) in the other context (context B). For no-extinction controls (NO-EXT, $n=$ 8 per condition), rats were placed in the chamber for the same amount of time, but were not exposed to the tone CS. Two days following conditioning, all rats were returned to the extinction context again and exposed to $45 \mathrm{CS}$-alone presentations.

\section{Data analysis}

Data analyses were performed as described in Experiment 1.

\section{Experiment 4: Is the immediate extinction deficit due to longer extinction-retention test interval?}

\section{Subjects and behavior apparatus}

The subjects were 32 adult male Long-Evans rats (250-330 g) obtained and housed as described in Experiment 1. The conditioning chambers described in Experiment 1 comprised the behavior apparatus.

\section{Procedure}

Rats were submitted to three phases of training: fear conditioning, extinction, and extinction-retention test. For fear conditioning, rats received five tone-foot shock trials in context A. Fifteen minutes (IMMED) or $24 \mathrm{~h}$ (DELAY) later, rats received 45 tone-alone presentations for fear extinction (EXT, $n=8$ per condition) in the other context (context B). For no-extinction controls (NO-EXT, $n=8$ per condition), rats were placed in the chamber for the same amount of time, but were not exposed to the tone CS. Two days following extinction, all rats were returned to the extinction context again and exposed to $45 \mathrm{CS}$-alone presentations.

\section{Data analysis}

Data analyses were performed as described in Experiment 1. Four animals were excluded from the final analyses because they failed to show evidence of successful conditioning $(n=3)$ or failed to show evidence of extinction $(n=1)$; these animals exhibited levels of freezing that were more than two standard deviations above or below their group means. Thus, the number of animals in each group was as follows: IMMED $/ \mathrm{EXT}=7, \mathrm{IMMED} / \mathrm{No}-\mathrm{EXT}=8$, $\mathrm{DELAY} / \mathrm{EXT}=7$, and DELAY $/$ No-EXT $=6$.

\section{Acknowledgment}

This work was supported by a grant from the National Institutes of Health (R01MH065961).

\section{References}

Bisson, J.I., Jenkins, P.L., Alexander, J., and Bannister, C. 1997. Randomised controlled trial of psychological debriefing for victims of acute burn trauma. Br. J. Psychiatry 171: 78-81.

Bouton, M.E. 2002. Context, ambiguity, and unlearning: Sources of relapse after behavioral extinction. Biol. Psychiatry 52: 976-986.

Bouton, M.E. 2004. Context and behavioral processes in extinction. Learn. Mem. 11: 485-494.

Bouton, M.E. and Garcia-Gutierrez, A. 2006. Intertrial interval as a contextual stimulus. Behav. Processes 71: 307-317.

Bouton, M.E., Mineka, S., and Barlow, D.H. 2001. A modern learning theory perspective on the etiology of panic disorder. Psychol. Rev. 108: 4-32.

Bouton, M.E., Westbrook, R.F., Corcoran, K.A., and Maren, S. 2006. Contextual and temporal modulation of extinction: Behavioral and biological mechanisms. Biol. Psychiatry 60: 352-360.

Carew, T.J., Pinsker, H.M., and Kandel, E.R. 1972. Long-term habituation of a defensive withdrawal reflex in aplysia. Science 175: 451-454.

Davis, M., Walker, D.L., and Myers, K.M. 2003. Role of the amygdala in fear extinction measured with potentiated startle. Ann. N. Y. Acad. Sci. 985: $218-232$.

Gray, M.J. and Litz, B.T. 2005. Behavioral interventions for recent trauma: Empirically informed practice guidelines. Behav. Modif. 29: 189-215.

Herry, C., Trifilieff, P., Micheau, J., Luthi, A., and Mons, N. 2006. Extinction of auditory fear conditioning requires MAPK/ERK activation in the basolateral amygdala. Eur. J. Neurosci. 24: 261-269.

Herry, C., Bach, D.R., Esposito, F., Di Salle, F., Perrig, W.J., Scheffler, K. Luthi, A., and Seifritz, E. 2007. Processing of temporal unpredictability in human and animal amygdala. J. Neurosci. 27: 5958-5966.

Hobin, J.A., Goosens, K.A., and Maren, S. 2003. Context-dependent neuronal activity in the lateral amygdala represents fear memories after extinction. J. Neurosci. 23: 8410-8416.

Ji, J. and Maren, S. 2007. Hippocampal involvement in contextual modulation of fear extinction. Hippocampus 17: 749-758.

Kalisch, R., Korenfeld, E., Stephan, K.E., Weiskopf, N., Seymour, B., and Dolan, R.J. 2006. Context-dependent human extinction memory is mediated by a ventromedial prefrontal and hippocampal network. $J$. Neurosci. 13: 9503-9511.

Kamprath, K. and Wotjak, C.T. 2004. Nonassociative learning processes determine expression and extinction of conditioned fear in mice. Learn. Mem. 11: 770-786.

Kim, J.J. and Jung, M.W. 2005. Neural circuits and mechanisms involved in Pavlovian fear conditioning: A critical review. Neurosci. Biobehav. Rev. 30: $182-202$.

LaBar, K.S., Gatenby, J.C., Gore, J.C., LeDoux, J.E., and Phelps, E.A. 1998. Human amygdala activation during conditioned fear acquisition and extinction: A mixed-trial fMRI study. Neuron 20: 937-945.

LeDoux, J.E. 2000. Emotion circuits in the brain. Annu. Rev. Neurosci. 23: 155-184.

Maren, S. 1998. Overtraining does not mitigate contextual fear conditioning deficits produced by neurotoxic lesions of the basolateral amygdala. J. Neurosci. 18: 3088-3097.

Maren, S. 2001. Neurobiology of Pavlovian fear conditioning. Annu. Rev. Neurosci. 24: 897-931.

Maren, S. 2005. Building and burying fear memories in the brain. Neuroscientist 11: 89-99.

Maren, S. and Chang, C.H. 2006. Recent fear is resistant to extinction. Proc. Natl. Acad. Sci. 103: 18020-18025.

Maren, S. and Quirk, G.J. 2004. Neuronal signalling of fear memory. Nat. Rev. Neurosci. 5: 844-852.

McNally, R.J. 2003. Psychological mechanisms in acute response to trauma. Biol. Psychiatry 53: 779-788.

McSweeney, F.K. and Swindell, S. 2002. Common processes may contribute to extinction and habituation. J. Gen. Psychol. 129: 364-400.

Milad, M.R. and Quirk, G.J. 2002. Neurons in medial prefrontal cortex signal memory for fear extinction. Nature 420: 70-74.

Milad, M.R., Wright, C.I., Orr, S.P., Pitman, R.K., Quirk, G.J., and Rauch, S.L. 2007. Recall of fear extinction in humans activates the ventromedial prefrontal cortex and hippocampus in concert. Biol. Psychiatry 62: 446-454.

Morris, R.W., Furlong, T.M., and Westbrook, R.F. 2005. Recent exposure to a dangerous context impairs extinction and reinstates lost fear reactions. J. Exp. Psychol. Anim. Behav. Process. 31: 40-55.

Myers, K.M. and Davis, M. 2007. Mechanisms of fear extinction. Mol. Psychiatry 12: 120-150.

Myers, K.M., Ressler, K.J., and Davis, M. 2006. Different mechanisms of fear extinction dependent on length of time since fear acquisition. Learn. Mem. 13: 216-223. 
Pare, D., Quirk, G.J., and LeDoux, J.E. 2004. New vistas on amygdala networks in conditioned fear. J. Neurophysiol. 92: 1-9.

Phelps, E.A., Delgado, M.R., Nearing, K.I., and LeDoux, J.E. 2004. Extinction learning in humans: Role of the amygdala and vmPFC. Neuron 43: 897-905.

Quirk, G.J. and Mueller, D. 2008. Neural mechanisms of extinction learning and retrieval. Neuropsychopharmacology 33: 56-72.

Quirk, G.J., Russo, G.K., Barron, J.L., and Lebron, K. 2000. The role of ventromedial prefrontal cortex in the recovery of extinguished fear. $J$. Neurosci. 20: 6225-6231.

Quirk, G.J., Garcia, R., and Gonzalez-Lima, F. 2006. Prefrontal mechanisms in extinction of conditioned fear. Biol. Psychiatry 60: 337-343.

Rothbaum, B.O. and Davis, M. 2003. Applying learning principles to the treatment of post-trauma reactions. Ann. N. Y. Acad. Sci. 1008: 112-121.

Santini, E., Ge, H., Ren, K., Pena de Ortiz, S., and Quirk, G.J. 2004. Consolidation of fear extinction requires protein synthesis in the medial prefrontal cortex. J. Neurosci. 24: 5704-5710.
Sotres-Bayon, F., Bush, D.E., and LeDoux, J.E. 2004. Emotional perseveration: An update on prefrontal-amygdala interactions in fear extinction. Learn. Mem. 11: 525-535.

Thierry, A.M., Gioanni, Y., Degenetais, E., and Glowinski, J. 2000. Hippocampo-prefrontal cortex pathway: Anatomical and electrophysiological characteristics. Hippocampus 10: 411-419.

Thompson, R.F. and Spencer, W.A. 1966. Habituation: A model phenomenon for the study of neuronal substrates of behavior. Psychol. Rev. 73: 16-43.

Wagner, A.R. 1982. SOP: A model of automatic memory processing in animal behavior. In Information processing in animals: Memory mechanisms (eds. N.E. Spear and R.R. Miller), pp. 5-47. Erlbaum, Hillsdale, NJ.

Received May 27, 2008; accepted in revised form October 23, 2008. 


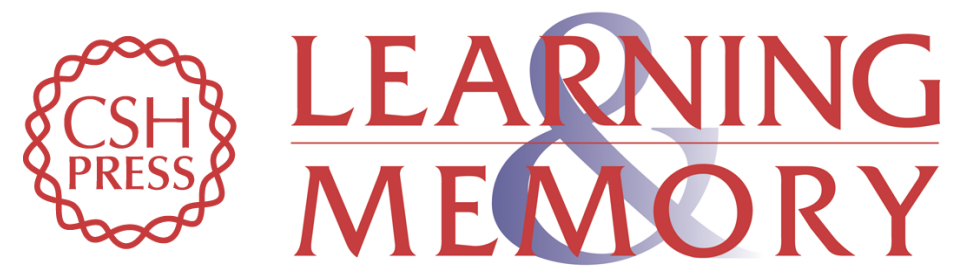

\section{Early extinction after fear conditioning yields a context-independent and short-term suppression of conditional freezing in rats}

Chun-hui Chang and Stephen Maren

Learn. Mem. 2009, 16:

Access the most recent version at doi:10.1101/lm.1085009

References This article cites 40 articles, 12 of which can be accessed free at: http://learnmem.cshlp.org/content/16/1/62.full.html\#ref-list-1

License

Email Alerting

Receive free email alerts when new articles cite this article - sign up in the box at the Service top right corner of the article or click here. 